\title{
Emulsion Polymerization of Butyl Acrylate: Safe Optimization Using Topological Criteria
}

\author{
Sabrina Copelli and Vincenzo Torretta \\ Dipartimento di Scienza e Alta Tecnologia, Università degli Studi dell'Insubria, via G.B. Vico 46, 21100 Varese, Italy
}

\author{
Angelo Lunghi
}

Divisione Stazione Sperimentale per i Combustibili, INNOVHUB, viale A. De Gasperi 3, 20097 S. Donato M.se, Italy

\author{
Marco Derudi, Carlo Sala Cattaneo, and Renato Rota* \\ Politecnico di Milano, Dipartimento di Chimica, Materiali e Ingegneria Chimica “G. Natta”, via Mancinelli 7, 20131 Milano, Italy
}

\begin{abstract}
Fast and strongly exothermic emulsion polymerization processes are particularly difficult to optimize from both safety and productivity points of view because of the occurrence of a number of undesired side reactions (e.g., propagation of tertiary radicals, chain transfer to monomer, backbiting, termination by disproportionation, etc.) and the triggering of boiling phenomena with consequent stable foam formation under atmospheric pressure. Therefore, it would be useful to develop a suitable combined theoretical and experimental procedure able to detect both the optimum process dosing time and initial reactor temperature. In this work, it is discussed how an extended version of the topological criterion theory, originally developed for isoperibolic semibatch reactors, can be used to safely optimize an indirectly cooled isothermal semibatch reactor. Moreover, such a methodology is applied to a case study represented by the synthesis of poly(butyl acrylate) through the radical emulsion polymerization of butyl acrylate.
\end{abstract}

\section{INTRODUCTION}

Runaway phenomena are a very common problem in pharmaceutical and fine chemical industries. However, despite only a small number of these accidents injuring workers or the inhabitants of the neighborhood of the damaged factory, when strong runaways occur, the consequences can be really serious. This has motivated the great amount of work that has been done on runaway phenomena for batch (B) and semibatch (SB) reactors during the last 30 years. ${ }^{1-11}$ Particularly, a general criterion able to detect the so-called "runaway boundary" in multiple reaction systems and different reactor typologies is the generalized parametric sensitivity criterion. ${ }^{4}$ This criterion identifies the runaway boundary looking for the maximum of a suitable objective sensitivity coefficient, the normalized sensitivity coefficient of the maximum reactor temperature with respect to any operating parameter. A different general criterion for determination of the runaway boundary is the divergence criterion. ${ }^{5-7}$ This criterion states that if the system of ordinary differential equations (ODEs) that describes the analyzed process exhibits positive divergence, the synthesis is operating under runaway conditions. The criterion shows the relevant advantage of being usable for both online and offline evaluations.

However, from a practical point of view, the optimization of all (or some) operating parameters (e.g., coolant temperature and dosing time) is the relevant aspect. Knowing the runaway boundaries allows one to avoid the selection of potentially hazardous operating conditions, but it does not allow one to optimize the analyzed process. The first combined "safety-optimization" approach for isoperibolic semibatch reactors (SBRs) was developed by Hugo and Steinbach. ${ }^{1}$ Their work, based on homogeneous systems, introduced the accumulation criterion for analysis of SBR thermal behavior: coreactant accumulation into the system, which arises from a nonegligible characteristic time of the chemical reaction with respect to that of the coreactant supply, must be kept at sufficiently low values to avoid the reactor thermal loss of control (runaway). According to this criterion, operating conditions characterized by a sufficiently low coreactant accumulation are considered not only safe but also productive. Steensma and Westerterp ${ }^{2}$ extended the results obtained by Hugo and Steinbach ${ }^{1}$ to heterogeneous (liquid-liquid) SBRs, introducing the concept of target temperature and producing the so-called boundary diagrams (BDs) for single reactions of $(1,1)$ reaction-order kinetics. Particularly, such diagrams are generated in a suitable dimensionless space that allows end users to easily discriminate between safe ("quick onset, fair conversion, and smooth temperature profile", QFS) and excessive accumulation operating conditions. According to the $\mathrm{BD}$ method, the QFS region is considered the most safe and productive for an exothermic SBR. However, it can be noted that the definition of such a region is somehow arbitrary. ${ }^{3}$ The problem of having an arbitrary definition of the QFS conditions was discussed by Alós et al., ${ }^{3}$ who proposed, for reacting systems involving a single reaction, a definition of QFS using a suitable objective function.

Special Issue: Giulio Sarti Festschrift

Received: September 2, 2012

Revised: December 23, 2012

Accepted: January 8, 2013

Published: January 8, 2013 
In particular, the QFS of an isoperibolic SBR is individuated, for a given value of the dosing time, by the coolant temperature in correspondence with which the objective function "time at which the maximum reactor temperature occurs" exhibits a local minimum. The intrinsic nature of this criterion can be proven by using parametric sensitivity. Recently, a more general optimization criterion, based on topological tools and able to consider different reactor typologies and temperature control modes, has also been developed. ${ }^{12,13}$

Polymerization processes are one of the industrial processes most frequently involved in thermal runaway accidents ${ }^{14}$ (that is, accidents involving an exothermic phenomenon caused by a loss of reactor temperature control that occurs whenever the heat evolution rate is higher than the removal one provided by a dedicated cooling system) for three main reasons: (1) polymerizations can exhibit high reaction enthalpies ${ }^{15}$ (up to $110 \mathrm{~kJ} / \mathrm{mol}$ ); (2) huge free-radical accumulation, due to both a termination reaction rate decrease and a propagation reaction rate increase (Trommsdorff or gel effect ${ }^{16,17}$ ), causes an autoacceleration of heat evolution; (3) under atmospheric pressure, boiling phenomena followed by stable foam formation can be triggered above a threshold temperature [in the following, referred to as MAT, the "maximum allowable temperature"18 (note that the MAT value could also be lower than such a value when reaction mixture decompositions or unwanted side reactions, such as the crosslinking ones) is triggered at lower temperatures], which is characteristic of the analyzed reacting system. Therefore, it is difficult to find a scale-independent optimization procedure able to identify the optimum values of the relevant operating variables (e.g., for a $\mathrm{SBR}$, the dosing time and initial reactor temperature values) in order to maximize both reactor safety and productivity.

Among all polymerization processes, emulsion polymerization is widely diffused around the world to produce waterborne resins with a great variety of colloidal and physicochemical properties. Particularly, colloidal properties of latex products are of great importance from both academic and industrial viewpoints. ${ }^{19}$ A generic heterogeneous free-radical polymerization involves emulsification of a relatively hydrophobic monomer in water by an oil-in-water emulsifier [e.g., sodium lauryl sulfate (SLS)], followed by the initiation reaction with either a water-soluble initiator [e.g., sodium persulfate or potassium persulfate (KPS)] or an oilsoluble initiator [e.g., 2,2' -azobis(isobutyronitrile) (AIBN)]. It is a complex process because nucleation, growth, and stabilization of polymer particles are controlled by the free-radical polymerization mechanisms in combination with various colloidal phenomena. The most striking feature seems to be the free-radical segregation among monomer-swollen polymer particles: this phenomenon greatly reduces the bimolecular termination probability and, therefore, it results in a faster polymerization rate and higher polymer molecular weight. ${ }^{19}$ This advantageous characteristic of emulsion polymerization cannot be achieved simultaneously in bulk or solution polymerization.

Industrially, because of the exothermic nature of free-radical polymerizations and the limited heat-transfer capacity in largescale reactors, most commercial latex products are manufactured by semibatch or continuous reaction systems. One of the main differences among the polymerization processes cited above is the growing particle residence time distribution within the reactor. Particularly, residence time distribution broadness is, in decreasing order, continuous $>$ semibatch. As a consequence, the resultant particle size distribution broadness is, in decreasing order, continuous $>$ semibatch. On the contrary, the polymerization rate generally follows the trend semibatch $>$ continuous. Furthermore, at the full-plant scale, reproducibility of emulsion polymerization processes within a narrow range is desirable; this means that the final solids content should be constant within $\pm 1 \%$, the particle size, emulsion viscosity, and polymer average molecular mass should vary little, and any residual monomer should be maintained within minimum possible narrow limits $(<0.5 \%)$. In order to achieve these conditions, the formulation of the emulsion polymerization (namely, the recipe) should not be subject to variations such as minor changes of either raw materials or operative conditions. ${ }^{20}$ Anyway, a certain degree of operational flexibility is usually permitted, and both semibatch and continuous emulsion polymerization processes can produce latex products with controlled polymer composition and particle morphology even if subjected to the minor changes cited above.

Moreover, other restrictions apply on an emulsion polymerization process in industrial practice: the process should be completed in the shortest possible time, and the latex concentration must be as high as possible. With regard to time, if the process is operated discontinuously, an overall time including loading of the chemicals, polymerizing, cooling, and unloading should be within $8-12 \mathrm{~h}$ to allow two or three shifts per day; on the contrary, if the process is operated continuously, the reactor residence time should be as short as possible, once taking into account a suitable reaction time. With regard to the latex concentration, it is desirable to prepare latex at the highest concentration possible to save time in production, unlike most theoretical works in laboratories. ${ }^{20}$ The upper limit of the maximum solids content is generally the high viscosity of the latex product, which prevents proper stirring and heat transfer, and the reactor temperature operating mode (e.g., the solids content for isoperibolic processes should be under $35 \%$, while for isothermal ones, it can be up to $55 \%)$.

Poly(butyl acrylate) (PBA) lattices are an interesting case study to investigate in detail the safe optimization of a generic emulsion polymerization process because its synthesis involves lots of substance loadings, heating and cooling steps, a quite high propagation reaction enthalpy, and a huge tendency to accumulate free radicals.

In this work, the topological criterion theory ${ }^{12,13}$ originally developed for isoperibolic SBRs has been extended to SBRs operated in the isothermal temperature control mode and, then, used to safely optimize the free-radical emulsion homopolymerization of butyl acrylate (BA) thermally initiated by KPS. Particularly, an indirectly cooled SBR (RC1, 1 L, Mettler Toledo) operated in the isothermal control mode (which is safer than the isoperibolic one for fast and exothermic polymerizations) has been chosen for the laboratory tests aimed to validate the developed optimization procedure. Because such an optimization procedure is scaleindependent, it can be easily used to identify the optimum operating conditions even for a full-plant reactor.

\section{EXTENDED TOPOLOGICAL CRITERION AND OPTIMIZATION PROCEDURE}

The topological criterion theory ${ }^{12,13}$ states that, for a semibatch process carried out under isoperibolic temperature control mode, the boundary between "runaway" (RW) and QFS ${ }^{21-25}$ conditions with respect to a desired product $\mathrm{X}\left(\mathrm{QFS}_{\mathrm{X}}\right)$ is identified by an inversion of the topological curve (TC) showing a concavity toward the right. Furthermore, as discussed in detail elsewhere, ${ }^{12,13}$ this curve shows all of the possible thermal behavior regions of an isoperibolic SBR obtainable by varying one system constitutive parameter (e.g., the dosing time) or initial condition (e.g., the initial reactor or coolant temperature) in a suitable range. The TC can be drawn by solving material and reactor 
energy balance equations describing the analyzed system for each investigated value of the generating parameter and then reporting onto a $2 \mathrm{D}$ diagram the ratio of the obtained reactor temperature maxima to the initial reactor temperature, $\psi_{\text {max, theo }}=$ $T_{\text {max,theo }} / T_{0}$, versus the conversion with respect to the desired product in correspondence with such maxima, $\zeta_{\mathrm{X}}\left(\psi_{\text {max,theo }}\right)$. In the presence of only one exothermic reaction (in the polymerization cases, the "global" propagation reaction), such a curve can be generated also experimentally ${ }^{25}$ by measuring, through a set of isoperibolic tests carried out in a laboratory calorimeter, the maximum reactor temperature, $T_{\text {max,exp, }}$ and the enthalpic conversion in correspondence with such a maximum, $\zeta_{\mathrm{cal}, \max }=$ $\int_{0}^{t_{\max }} \dot{Q}_{\mathrm{rxn}}(t) \mathrm{d} t / \Delta \hat{H}_{\mathrm{rxn}} m$.

Moreover, it can be shown that, whenever a TC whose generating parameter is the dosing time exhibits an inversion with concavity toward the left, one of the following system thermal behavior boundaries is encountered: transition (the system thermal loss of control shifts its occurrence from times lower/larger than the dosing period to times larger/lower) or starving (the system state shifts from QFS conditions to low-productivity operating conditions characterized by a squared pseudostationary reactor temperature profile and a forced linear conversion during the dosing period).

It has been also demonstrated ${ }^{26}$ that the topological criterion theory for QFS detection does not depend on the particular system of ODEs used to describe the process dynamics provided that only two dependent variables contribute effectively to characterize the system thermal behavior: temperature and conversion with respect to the desired product X. Such variables appear in all possible systems of equations writable to describe a generic-complex-controlled process: they can be referred to as "core constants". Accounting for this feature, dosing stream and jacket temperature control equations, mixing rules for volume determination, global material, and jacket energy balance equations can be added to the system of ODEs describing an isoperibolic SBR without invalidating the topological criterion; this leads to an "extended form" of the topological criterion.

Accordingly, in this paper the topological criterion has been extended to optimize semibatch processes operated in the isothermal temperature control mode. Along the same lines as those used for developing the original topological criterion, the developed optimization procedure is based on analysis of the TC: the QFS inversion is considered to be a boundary beyond which the optimum operating conditions (that is, the dosing time and initial reactor temperature) can be searched, accounting for both the MAT value and all of the desired productivity and quality constraints.

Moreover, because we are dealing with controlled isothermal processes, we expect that before the QFS inversion, a "loss of control" (LoC) happens involving a more general behavior than that identified for isoperibolic SBRs, where the loss of thermal control is always associated with a sharp temperature peak. In controlled isothermal SBRs, a loss of thermal control can lead either to a sharp temperature peak or simply to a loss of the temperature set point. The latter situation is obviously less dangerous than the first one, where a real thermal explosion can arise if the venting system is not able to deal with the reactor pressurization, but it cannot be considered suitable for operating the reactor from neither a product quality nor a safety point of view.

Because no real control systems can maintain the reactor temperature value exactly equal to the set point, it is necessary to define a range around the set point beyond which a LoC is assumed. In this work, a maximum reactor temperature fluctuation of $2.5^{\circ} \mathrm{C}$ has been assumed as the threshold value that, if overcome, evidences a LoC situation independently on the temperature versus time profiles.

The combined theoretical-experimental optimization procedure proposed for a controlled isothermal SBR involves six main steps, and it is summarized in the synoptic of Figure 1.

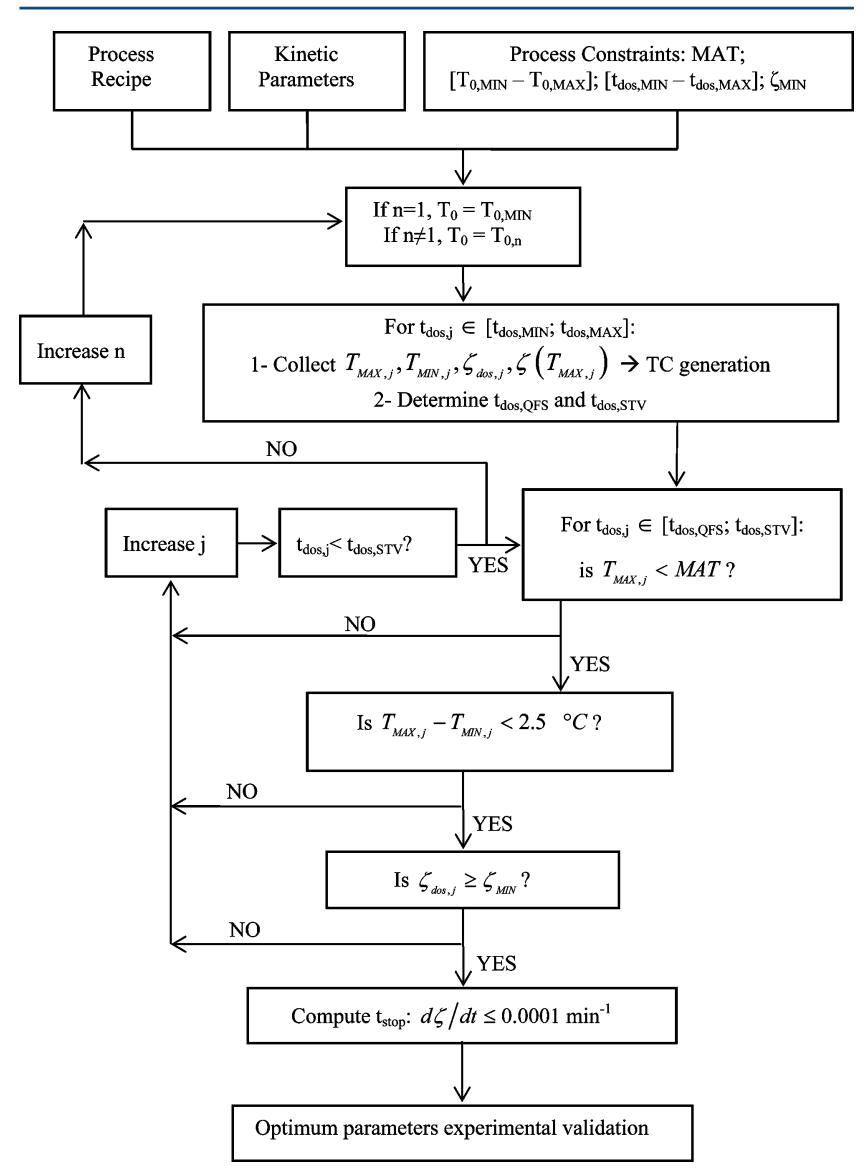

Figure 1. Isothermal optimization procedure scheme.

Step 1. Definition of the recipe. Provided that the reactor typology (semibatch) and the temperature control mode (isothermal) are given, the operational list (that is, the recipe) has to be defined together with the successive computation of the cooling system characteristics (e.g., jacket volume, coolant flow rate, coolant saturation temperatures, etc.). This information will be used for both theoretical simulations and laboratory tests.

Step 2. Execution of calorimetric screening tests. This step allows for both characterization of all substances thermal behavior in the selected temperature range and MAT determination.

In particular, dynamic and isothermal differential scanning calorimetry (DSC) experiments must be performed on reactants and additives to detect if any thermal decomposition or oxidation can be triggered. Moreover, a set of batch isoperibolic syntheses at different coolant temperatures should be carried out to detect the minimum temperature in correspondence with which the reaction mixture, under atmospheric pressure, starts to boil, vigorously forming foams. Batch conditions have been selected because it is known that they are the most dangerous from the thermal stability point of view.

Step 3. Estimation of reaction rate parameters and masstransfer coefficients. This step can be performed either experimentally (through a data fitting of adiabatic, isoperibolic, or 
isothermal tests) or theoretically (looking for the required parameters in the literature).

With regard to the experiments, a single isoperibolic laboratory test (RW and starving conditions must be obviously avoided) must be carried out with RC1 equipment. However, if the isoperibolic test does not cover the full temperature range of interest, either PHI-TEC II or ARC adiabatic tests can be used for to obtain the data needed for kinetic parameter fitting in the entire range of normal and upset operating temperatures. However, if the process is critical from the thermal stability point of view and neither adiabatic nor isoperibolic tests can be carried out safely, also isothermal tests at different initial reactor temperatures can be used for data fitting.

Step 4. Determination of the optimum initial reactor temperature-dosing time couple at the laboratory scale. This is the core of the optimization procedure. It must be carried out through the simulation model until convergence is reached, and it is based on the following substeps.

Substep a. Definition of suitable initial reactor temperature $\left(T_{0, \text { min }}\right.$ and $\left.T_{0, \text { max }}\right)$ and dosing time $\left(T_{\text {dos,min }}\right.$ and $\left.T_{\text {dos,max }}\right]$ ranges and selection of the iterating parameter in the optimization procedure and of the generating parameter of the TC. It should be noted that because polymerization reactions require a high product quality (e.g., peaked molecular weight distribution, high average molecular weight, little branching, etc.), which can be obtained only by limiting as much as possible temperature fluctuations, the initial reactor temperatures are forced to vary into a narrow range. For this reason, the initial reactor temperature is not a suitable parameter for generating a TC because the generating parameter must be varied in a sufficiently wide range (conversely, the TC would be incomplete and, consequently, useless). Therefore, the dosing time, which can be varied in a wide range, has been chosen as the generating parameter of the TC, and the initial reactor temperature has been selected as the iterating parameter in the optimization procedure.

Moreover, a minimum threshold value for the conversion of species $\mathrm{X}$ at the end of the dosing time, $\zeta_{\mathrm{X}, \min }$, has to be defined.

Substep $\mathrm{b}$. Identification of the dosing time values for $\mathrm{QFS}_{\mathrm{X}}$ $\left(t_{\text {dos, QFFS }}\right)$ and for starving $\left(t_{\text {dos,STV }}\right)$ conditions in the TC. Through the procedure discussed elsewhere ${ }^{12,13}$ and using a given temperature value (starting from the lower one allowed), a TC has to be generated to bind the QFS operating region (namely, the one whose dosing time ranges between $t_{\mathrm{dos}, \mathrm{QFS}_{\mathrm{X}}}$ and $t_{\mathrm{dos}, \mathrm{STV}}$ ), where the optimum dosing time at the current reactor temperature has to be searched for.

Substep c. Verification of the MAT constraint. For increasing dosing times into the QFS operating region, the computed maximum reactor temperatures, $T_{\max , j}$, have to be checked for fulfillment of the constraint:

$$
T_{\max , j}<\text { MAT }
$$

If it is found that, for all of the allowed dosing times, $T_{\max , j}>$ MAT, the initial reactor temperature should be increased and substep $b$ repeated with this new value.

Substep d. Verification of the LoC constraint. In this substep, it is necessary to check that the following constraint is fulfilled, where $T_{\max , j}$ is the computed maximum reactor temperature and $T_{\text {max }, j}$ the computed minimum reactor temperature:

$$
\Delta T=T_{\max , j}-T_{\min , j} \leq 2.5^{\circ} \mathrm{C}
$$

If it is found that this constraint is not fulfilled, the dosing time has to be increased and substep c repeated with this new value.
Substep e. Verification of the $\zeta_{\mathrm{X} \text {,min }}$ constraint. As a final check, conversion of the target species $\mathrm{X}$ at the end of the dosing time, $\zeta_{\mathrm{X}, \mathrm{dos}, \mathrm{j}}$, is required to be larger than a given threshold value, $\zeta_{\mathrm{X}, \mathrm{min}}$ :

$$
\zeta_{\mathrm{X}, \mathrm{dos}, j} \geq \zeta_{\mathrm{X}, \min }
$$

If this is not true, the dosing time has to be increased and substep $\mathrm{c}$ repeated. If all $\zeta_{\mathrm{X}, \mathrm{dos}, \mathrm{j}}<\zeta_{\mathrm{X}, \mathrm{min}}$, the initial reactor temperature should be increased and substep $b$ repeated.

Step 5. Stop time determination. Once the optimum initial reactor temperature and dosing time have been determined, the maximum time at which the process has to be stopped must be identified. Such a time can be defined as that corresponding to conversion variations lower than $0.0001 \mathrm{~min}^{-1}$, that is, to a negligible production rate. Experimentally, such a time can be identified when there are no more reactor temperature fluctuations (that is, temperature fluctuations are within normal temperature background noise). From a practical point of view, in these conditions, the process may be meaningless and the real stop time (lower than both of these two values) should be determined by a cost/benefit analysis.

Step 6. Experimental validation at laboratory scale. Finally, the optimum laboratory initial reactor temperature and dosing time must be experimentally validated through an isothermal RC1 test carried out at these operating conditions.

Once the procedure has been validated for the recipe of interest, it is possible to take advantage of its scale insensitivity to repeat steps 1,4 , and 5 for identifying the optimum operating parameters for the real-scale SBR.

\section{RESULTS}

As mentioned before, the BA emulsion polymerization case study has been investigated to assess the practical feasibility of the optimization procedure proposed in section 2 and to validate its results.

3.1. Experimental Setup. In order to perform a PBA laboratory synthesis as close as possible to that usually carried out at an industrial scale, RC1 equipment (MP06, $1 \mathrm{~L}$, Mettler Toledo), indirectly cooled by means of an external jacket, has been used with the following operational list: (1) distilled water (W, continuous medium), SLS (surfactant), and sodium carbonate $\left(\mathrm{Na}_{2} \mathrm{CO}_{3}\right.$, buffer $)$ loaded into the reactor and then heated to a reactor set-point temperature $\left(70,75\right.$, or $\left.78{ }^{\circ} \mathrm{C}\right)$ in 35-40 min, activating an isothermal temperature control mode; (2) reaction mixture kept at the set-point temperature for 20-30 min in order to facilitate SLS micelles formation; (3) KPS loaded in one shot into the reactor, providing a waiting time of $20 \mathrm{~min}$ to allow for the reactor temperature reequilibration at its set-point value; (4) BA dosed through a pump.

Reactants and reactor characteristics are summarized in Table 1.

3.2. Calorimetric Screening Tests. In order to characterize the thermal behavior of all of the substances involved in the process and to identify the MAT value, DSC tests and a set of 50 $\mathrm{mL}$ scale isoperibolic syntheses at different coolant temperatures have been carried out.

In particular, dynamic DSC tests have been performed on KPS and SLS (as discussed elsewhere ${ }^{27}$ ), while a set of isothermal DSC tests have been carried out on BA (Figure 2) using a Mettler Toledo DSC 823 apparatus and stainless steel, medium-pressure Viton/120 $\mu \mathrm{L}$ crucibles. All DSC tests have been performed under a nitrogen atmosphere to avoid eventual oxygen contributions.

It has been found that KPS exhibits an exothermic effect in correspondence with $188^{\circ} \mathrm{C}$. Such a phenomenon can be ascribed 
Table 1. Process Recipe and Reactor Characteristics for the Free-Radical Emulsion Homopolymerization of BA Thermally Initiated by KPS

\begin{tabular}{|c|c|c|c|}
\hline \multicolumn{4}{|c|}{ Initial Load } \\
\hline $283 \mathrm{~g}$ & water & $0.5 \mathrm{~g}$ & $\mathrm{Na}_{2} \mathrm{CO}_{3}$ \\
\hline $3.0 \mathrm{~g}$ & SLS & $1.2 \mathrm{~g}$ & KPS \\
\hline \multicolumn{4}{|c|}{ Dosed Stream } \\
\hline \multirow{2}{*}{\multicolumn{4}{|c|}{$\begin{array}{l}\text { BA } \\
\text { Reactor and Cooling System }\end{array}$}} \\
\hline & & & \\
\hline $\begin{array}{l}\text { reactor nominal } \\
\text { volume }\end{array}$ & $1.0 \times 10^{-3} \mathrm{~m}^{3}$ & $\begin{array}{l}\text { jacket nominal } \\
\text { volume }\end{array}$ & $5.0 \times 10^{-4} \mathrm{~m}^{3}$ \\
\hline cooling & $\begin{array}{c}\text { external } \\
\text { jacket }\end{array}$ & coolant flow rate & $\begin{array}{c}5.0 \times 10^{-4} \\
\mathrm{~m}^{3} / \mathrm{s}\end{array}$ \\
\hline coolant & silicon oil & $\mathrm{UA}_{0}$ & $\begin{array}{l}2.33-2.43 \\
\mathrm{~W} / \mathrm{K}\end{array}$ \\
\hline
\end{tabular}
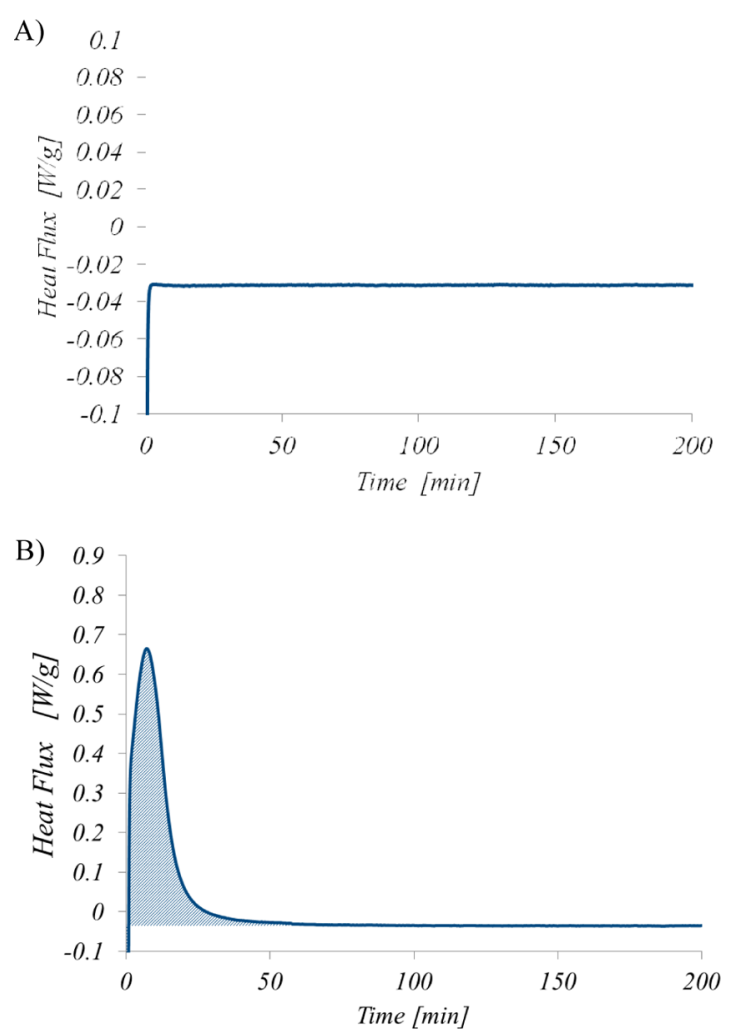

Figure 2. Isothermal DSC characterization of $B A$ in a nitrogen atmosphere: (A) without initiator, sample amount $=4.98 \mathrm{mg}$, and investigated temperature $=70^{\circ} \mathrm{C}$; (B) with AIBN as the initiator, sample amount $=2.5 \mathrm{mg}$, and investigated temperature $=70^{\circ} \mathrm{C}$.

to thermal decomposition of the crystalline solid. On the contrary, SLS exhibits two endothermic effects (the former at about $47{ }^{\circ} \mathrm{C}$ and the latter at about $92{ }^{\circ} \mathrm{C}$ ). Such phenomena correspond to a solid-phase transition between two different crystalline phases and a melting phase, respectively. ${ }^{27}$

With regard to $\mathrm{BA}$, it can be observed from the isothermal DSC test reported in Figure 2A that no self-initiated polymerization reactions occur at the selected temperature $\left(70^{\circ} \mathrm{C}\right)$ for all of the investigated time; it is necessary to add an organic-soluble initiator (in this case AIBN) in order to observe a polymerization reaction (see Figure 2B). The same behavior is observed at 75 and $78{ }^{\circ} \mathrm{C}$.

With particular reference to the MAT parameter determination, a set of three isoperibolic 50-mL-scale tests at different coolant temperatures, respectively 70,75 , and $78^{\circ} \mathrm{C}$, have been carried out. Particularly, a $100 \mathrm{~mL}$ flask (supplied with a thermocouple connected with an automatic temperature data recorder and a magnetic stirrer) has been inserted into a thermostatic water bath, whose temperature has been maintained at the desired set-point temperature (to realize the isoperibolic mode), and loaded with $24.25 \mathrm{~g}$ of a water/SLS emulsion previously prepared. When water bath and flask thermocouple equilibria are reached, $17 \mathrm{~g}$ of monomer is loaded into the flask, and a new thermocouple equilibration is expected. Then $0.1 \mathrm{~g}$ of KPS are added in one shot.

The main experimental conditions and results are summarized in Table 2, which lists the recipe, set point of the coolant

Table 2. Process Recipe and Coolant and Reaction Mixture Boiling Temperatures for the Investigated 50-mL-Scale BA Emulsion Homopolymerization Synthesis

\begin{tabular}{clcc}
\multicolumn{3}{c}{ Recipe } \\
$24.0 \mathrm{~g}$ & water & $0.10 \mathrm{~g}$ & $\mathrm{KPS}$ \\
$0.25 \mathrm{~g}$ & $\mathrm{SLS}$ & $17.0 \mathrm{~g}$ & $\mathrm{BA}$ \\
$0.07 \mathrm{~g}$ & $\mathrm{Na}_{2} \mathrm{CO}_{3}$ & \\
& Set of 50 - $\mathrm{mL}-$ Scale Synthesis & \\
run & $T_{\text {cooling }}\left({ }^{\circ} \mathrm{C}\right)$ & $T_{\text {boiling }}\left({ }^{\circ} \mathrm{C}\right)$ \\
1 & 70 & 85.2 \\
2 & 75 & 86.2 \\
3 & 78 & 85.9 \\
\hline
\end{tabular}

temperatures for each synthesis, and temperature values at which boiling phenomena (if any) have been observed. It is possible to see that the minimum temperature at which the reaction mixture

Table 3. Constitutive Model and Kinetic Parameters for the Free-Radical Emulsion Homopolymerization of BA Thermally Initiated by KPS $^{a}$

\begin{tabular}{|c|c|c|c|}
\hline$A_{i}$ & $s^{-1}$ & $8.00 \times 10^{15}$ & 28 \\
\hline$E_{i}$ & $\mathrm{~kJ} / \mathrm{kmol}$ & $1.62 \times 10^{5}$ & 28 \\
\hline$f$ & & 0.60 & 28 \\
\hline$A_{\mathrm{p}}^{\mathrm{s}}$ & $3 /(\mathrm{kmol} \mathrm{s})$ & $2.21 \times 10^{7}$ & 29 \\
\hline$E_{\mathrm{p}}^{\mathrm{s}}$ & $\mathrm{kJ} / \mathrm{kmol}$ & $1.79 \times 10^{4}$ & 29 \\
\hline$A_{\mathrm{p}}^{\mathrm{t}}$ & $\mathrm{m}^{3} /(\mathrm{kmol} \mathrm{s})$ & $1.52 \times 10^{6}$ & 30 \\
\hline$E_{\mathrm{p}}^{\mathrm{t}}$ & $\mathrm{kJ} / \mathrm{kmol}$ & $2.89 \times 10^{4}$ & 30 \\
\hline$A_{\mathrm{bb}}$ & $\mathrm{m}^{3} /(\mathrm{kmol} \mathrm{s})$ & $4.84 \times 10^{7}$ & 30 \\
\hline$E_{\mathrm{bb}}$ & $\mathrm{kJ} / \mathrm{kmol}$ & $3.17 \times 10^{4}$ & 30 \\
\hline$A_{\mathrm{t}}^{\mathrm{ss}}$ & $\mathrm{m}^{3} /(\mathrm{kmol} \mathrm{s})$ & $1.34 \times 10^{9}$ & 31 \\
\hline$E_{\mathrm{t}}^{\mathrm{ss}}$ & $\mathrm{kJ} / \mathrm{kmol}$ & $5.60 \times 10^{3}$ & 31 \\
\hline$A_{\mathrm{t}}^{\mathrm{st}}$ & $\mathrm{m}^{3} /(\mathrm{kmol} \mathrm{s})$ & $2.74 \times 10^{8}$ & 30 \\
\hline$E_{\mathrm{t}}^{\mathrm{st}}$ & $\mathrm{kJ} / \mathrm{kmol}$ & $5.60 \times 10^{3}$ & 30 \\
\hline$A_{\mathrm{t}}^{\mathrm{tt}}$ & $\mathrm{m}^{3} /(\mathrm{kmol} \mathrm{s})$ & $1.80 \times 10^{7}$ & 30 \\
\hline$E_{\mathrm{t}}^{\mathrm{tt}}$ & $\mathrm{kJ} / \mathrm{kmol}$ & $5.60 \times 10^{3}$ & 30 \\
\hline$k_{\text {nucl,omo }}$ & & $6.01 \times 10^{-3}$ & this work \\
\hline$f_{\text {nucl,mic }}$ & & $1.00 \times 10^{-5}$ & this work \\
\hline$k_{\text {coal }}$ & $\mathrm{m}^{3} / \mathrm{s}$ & $2.80 \times 10^{-28}$ & this work \\
\hline$D_{\text {diff,wp }}$ & $\mathrm{m}^{2} / \mathrm{s}$ & $3.91 \times 10^{-10}$ & this work \\
\hline$D_{\text {diff,pw }}$ & $\mathrm{m}^{2} / \mathrm{s}$ & $3.10 \times 10^{-10}$ & this work \\
\hline$\Delta H_{\mathrm{rxn}}$ & $\mathrm{kJ} / \mathrm{mol}$ & 64.6 & this work \\
\hline$\varepsilon$ & & 0.6964 & this work \\
\hline$R_{\mathrm{H}}$ & & 0.5613 & this work \\
\hline $\mathrm{UA}_{\mathrm{ext}}$ & & 0.4200 & this work \\
\hline$\alpha$ & & 0.1530 & this work \\
\hline$r_{\text {mic }}$ & $\mathrm{M}$ & $2.50 \times 10^{-9}$ & 32 \\
\hline$E_{\mathrm{w}, \text { sat }}$ & $\mathrm{kmol} / \mathrm{m}^{3}$ & $2.43 \times 10^{-9}$ & 32 \\
\hline
\end{tabular}

a In the last column, "this work" means that the value has been estimated by fitting a set of isothermal RC1 data. 
starts to boil vigorously is equal to about $85{ }^{\circ} \mathrm{C}$. Such a temperature can be considered, as a first approximation, to be the MAT parameter value because no other side reactions, such as cross-linking reactions, have been observed (these reactions start to occur at temperatures much higher than $85-90{ }^{\circ} \mathrm{C}$ and, therefore, they can be disregarded without a loss of reliability of the kinetic model).

3.3. Kinetics Determination. Because the adiabatic temperature rise for this BA emulsion polymerization is equal to about $95{ }^{\circ} \mathrm{C}$, it is not possible to perform an adiabatic $\mathrm{RC} 1$ test to determine the reaction kinetics because boiling phenomena would start before the reaction completion. The same risk can be encountered even with an isoperibolic RC1 experiment (see section 3.2 with regard to isoperibolic tests at $50 \mathrm{~mL}$ scale); therefore, a series of three isothermal tests at different initial reactor temperatures and dosing times (that is, $70^{\circ} \mathrm{C}$ and $60 \mathrm{~min}$, $75^{\circ} \mathrm{C}$ and $40 \mathrm{~min}$, and $78^{\circ} \mathrm{C}$ and $30 \mathrm{~min}$ ) have been carried out. Using these $\mathrm{RC} 1$ tests and the mathematical model reported in Appendix A, a data fitting of the constitutive model parameters summarized in Table 3 has been performed. It is worthwhile to note that the mathematical model used in this work (see equations in Appendix A) is able to fully represent the polymerization process in an isothermal SBR, including dosing policy, temperature control loop, volumetric mixing rules, and polymer particle radius evolution.

3.4. Process Optimization. Using the model parameters summarized in Table 3, a series of TCs have been generated (see Figure 3 ) by solving the equations summarized in Appendix

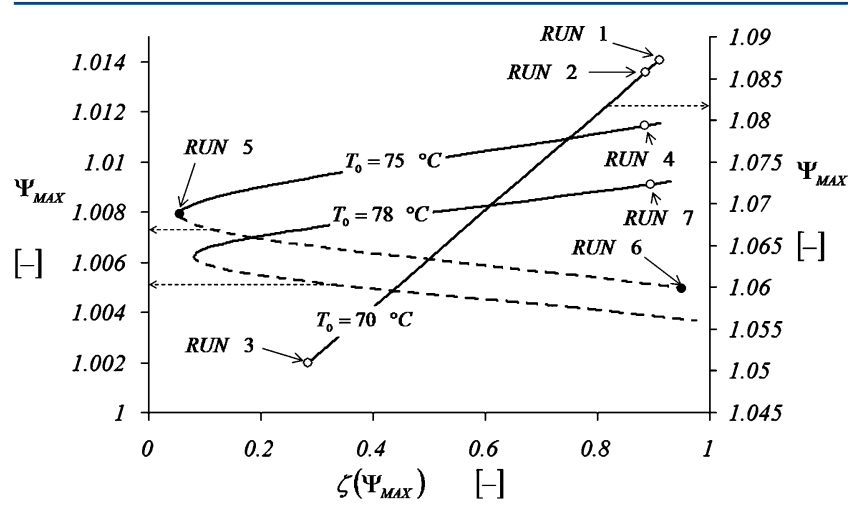

Figure 3. TCs (-, LoC region; - - -, QFS region) at different initial reactor temperatures for the free-radical emulsion homopolymerization of BA thermally initiated by KPS. $T_{0}=70,75$, and $78{ }^{\circ} \mathrm{C}$, $t_{\text {dos }}=5-60 \mathrm{~min}$, and model parameters as in Table 3. Experimental runs are reported according to the following criterion: $(\mathrm{O}) \mathrm{LoC}$ run; $(\bullet)$ QFS run.

A for different initial reactor temperatures (that is, 70, 75, and $78^{\circ} \mathrm{C}$, respectively) and using dosing times as TC generating parameters (from $t_{\mathrm{dos}, \min }=5 \mathrm{~min}$ up to $t_{\mathrm{dos}, \max }=60 \mathrm{~min}$, with steps of $150 \mathrm{~s}$ ).

We can see that for $T_{0}=70{ }^{\circ} \mathrm{C}$ neither transition, QFS, nor starving inversions occur in the investigated dosing time range. Such a thermal behavior indicates that the reaction is always carried out under high accumulation conditions because the set point of the reactor temperature is too low and, consequently, LoC operating conditions always dominate and no optimum dosing time can be detected. However, for TC generated at $T_{0}=75$ and $78^{\circ} \mathrm{C}$, there is a clear QFS inversion, in correspondence with which there is a transition between LoC and QFS conditions. No starving inversion has been detected in the investigated dosing time range for analyzed initial reactor temperatures.

After this preliminary evaluation aimed at characterizing the analyzed system thermal behavior, it is possible to perform the optimization procedure previously presented. Therefore, an optimum dosing time has been iteratively searched for, starting from $T_{0}=70$ and $78{ }^{\circ} \mathrm{C}$, by checking constraints (1)-(3) from the dosing time at which the QFS inversion occurs, $t_{\mathrm{dos}, \mathrm{QFS}}$ (QFS point in Figure 3 ) to $t_{\text {dos,max }}$ (because no starvation inversion has been detected). For $T_{0}=70{ }^{\circ} \mathrm{C}$, no QFS inversion can be detected, and therefore the optimization algorithm continues to increase the initial reactor temperature. For $T_{0}=75^{\circ} \mathrm{C}$, the QFS boundary is detected for a dosing time equal to $40 \mathrm{~min}$. In correspondence with this point, a local minimum (because it refers to the investigated dosing time range) of the conversion with respect to the desired polymer species has been observed. The minimum dosing time, able to satisfy constraints (1)-(3), has been found to be equal to $60 \mathrm{~min}$. This dosing time can be considered optimized from both safety $\left(T_{\text {max, theo }}=76^{\circ} \mathrm{C}<\right.$ $\left.\mathrm{MAT}=85^{\circ} \mathrm{C}\right)$ and productivity $\left(\zeta_{\text {dos,theo }}=0.937>\zeta_{\min }=0.930\right)$ points of view. Moreover, the run can be considered to be controlled (that is, no LoC is evidenced) because $\Delta T \sim 1.5^{\circ} \mathrm{C} \leq$ $2.5^{\circ} \mathrm{C}$.

3.5. Stop-Time Determination. The time at which the batch period (which follows the dosing period) can be terminated is referred to as the stop time, and it is defined as that corresponding to a conversion variation lower than $0.0001 \mathrm{~min}^{-1}$. In this case, it is equal to about $70 \mathrm{~min}$. Using the aforementioned experimental criterion related to the temperature fluctuations, the stop time has been found to be equal to about $75 \mathrm{~min}$, in fair agreement with the value predicted by the model. Of course, as previously mentioned, the real stop time can be lower than these values, and it must be determined by a cost/benefit analysis.

3.6. Experimental Validation. Both the theoretical TC and optimum $\left(T_{0, \text { opt }}\right.$ and $\left.t_{\text {dos,opt }}\right)$ couple have been validated through a set of isothermal RC1 runs, whose initial reactor temperature and dosing time values cover the range used to generate the TC.

In particular, seven isothermal experiments, summarized in Table 4, have been carried out. The corresponding experimental

Table 4. Comparison between Model Predictions and Experimental Results for the Free-Radical Emulsion Homopolymerization of BA Thermally Initiated by KPS ${ }^{a}$

\begin{tabular}{|c|c|c|c|c|c|c|c|c|}
\hline run & $T_{0}\left({ }^{\circ} \mathrm{C}\right)$ & $t_{\mathrm{dos}}(\min )$ & $\Delta T\left({ }^{\circ} \mathrm{C}\right)$ & $\zeta_{\text {max }, \text { cal }}$ & $\zeta_{\text {dos,exp }}$ & exp class & model class & notes \\
\hline 1 & 70 & 10 & 30.2 & 0.908 & 0.005 & LoC & LoC & strong boiling and foam formation \\
\hline 2 & 70 & 20 & 30.1 & 0.883 & 0.000 & LoC & LoC & strong boiling and foam formation \\
\hline 3 & 70 & 60 & 16.7 & 0.286 & 0.937 & LoC & LoC & moderate boiling and foam \\
\hline 4 & 75 & 20 & 4.2 & 0.913 & 0.840 & LoC & LoC & no boiling, no foam \\
\hline 5 & 75 & 40 & 2.9 & 0.056 & 0.934 & LoC & LoC/QFS & no boiling, no foam \\
\hline 6 & 75 & 60 & 1.8 & 0.955 & 0.936 & QFS & QFS & no boiling, no foam \\
\hline 7 & 78 & 30 & 3.3 & 0.931 & 0.884 & LoC & LoC & incipient boiling, no foam \\
\hline
\end{tabular}

${ }^{a_{T}}$ The consequences of each run have been reported by specifying the level of risk associated with the specific operating conditions. 
temperature and enthalpic conversion versus time profiles are shown in Figure 4, while Table 4 also reports, for each experiment,

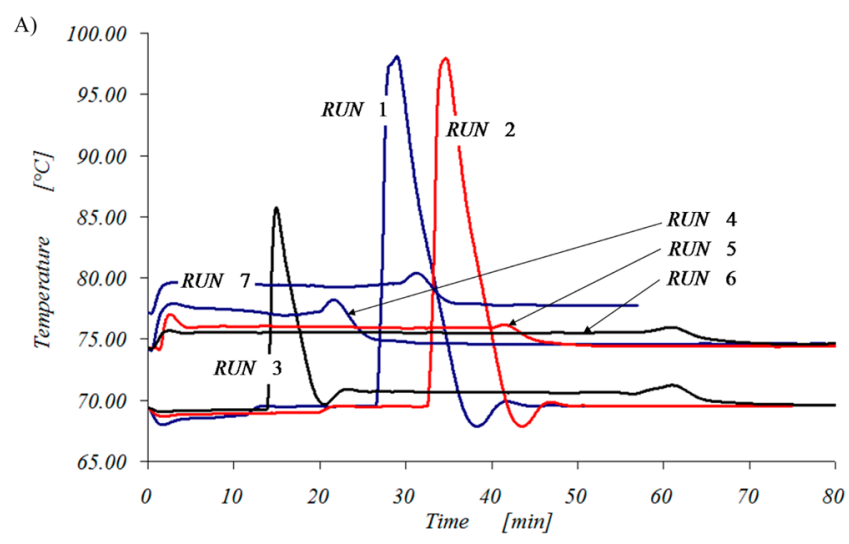

B)

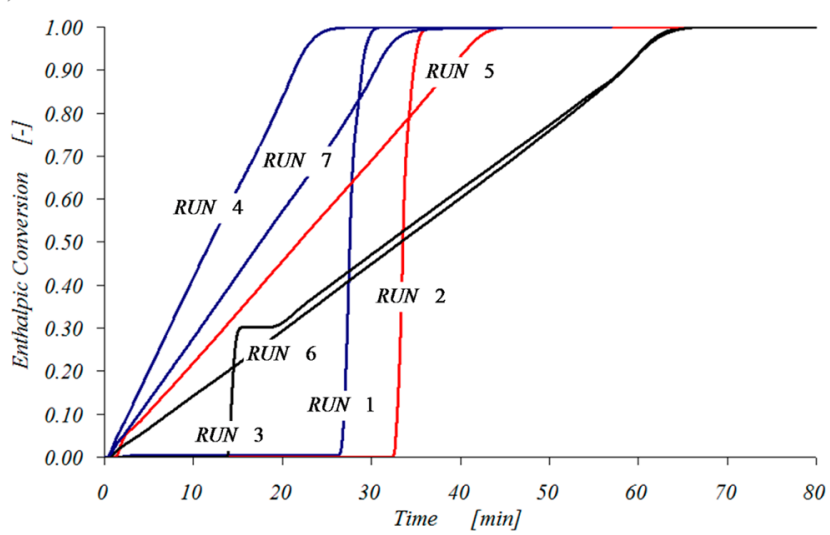

Figure 4. Experimental temperature (A) and enthalpic conversion (B) versus time profiles for the free-radical emulsion homopolymerization of BA thermally initiated by KPS (experimental details as in Tables 3 and 4).

the difference between the maximum and minimum reactor temperatures $\left(\Delta T=T_{\max , \exp }-T_{\min \text {,exp }}\right)$ and the enthalpic conversion corresponding to both the time at maximum temperature $\left(\zeta_{\mathrm{cal}, \max }\right)$ and the end of the dosing period $\left(\zeta_{\text {dosexp }}\right)$. Moreover, the same table also compares the theoretical and experimental classification of each run in terms of thermal behavior (LoC or QFS). Each ( $T_{\text {max, exp }}$ and $\left.\zeta_{\text {cal,max }}\right)$ couple has been located on the diagram reported in Figure 3. From these results, we can see that $T_{0, \text { opt }}=75^{\circ} \mathrm{C}$ and $t_{\text {dos,opt }}=$ $60 \mathrm{~min}$, which are the optimum operating parameter values calculated from the optimization procedure and are identified as optimal also from the experiments because all thermal, productivity, and control definition constraints are fulfilled (see Table 4). Moreover, the boundary between the LoC and QFS thermal behavior is the same from both model and experimental analysis, as can be seen in Figure 3. These cross-validations strongly support the reliability of the obtained results.

\section{CONCLUSIONS}

In this work, it has been shown that the topological criterion theory, originally developed for isoperibolic SBRs, can be successfully extended to isothermal reacting systems when providing all of the necessary equations (e.g., the temperature control mode) needed to simulate the whole process. Moreover, a suitable combined experimental-theoretical optimization procedure has been developed and validated using several RC1 tests at different initial reactor temperatures and dosing times. Particularly, the case study of BA emulsion homopolymerization thermally initiated by KPS has been analyzed showing a good agreement between the theoretical predictions (namely, the shape of the TC and its thermal behavior regions) and the experimental results.

\section{APPENDIX A: MATHEMATICAL MODEL}

The following kinetic scheme summarizes the main reactions considered in the PBA synthesis:

$$
\begin{array}{ll}
\text { 1. Initiation } & \mathrm{I}_{2} \stackrel{k_{i}}{\rightarrow} 2 \mathrm{R}_{\mathrm{s}} \\
\text { 2. Propagation } & \mathrm{R}_{\mathrm{s}}+\mathrm{M} \stackrel{k_{\mathrm{p}}^{\mathrm{s}}}{\rightarrow} \mathrm{R}_{\mathrm{s}} \\
\text { 3. Backbiting } & \mathrm{R}_{\mathrm{s}} \stackrel{k_{\mathrm{bb}}}{\rightarrow} \mathrm{R}_{\mathrm{t}}
\end{array}
$$

4. Propagation from tertiary radicals

$$
\mathrm{R}_{\mathrm{t}}+\mathrm{M} \stackrel{k_{\mathrm{p}}^{\mathrm{t}}}{\rightarrow} \mathrm{R}_{\mathrm{s}}+\mathrm{SCB}
$$

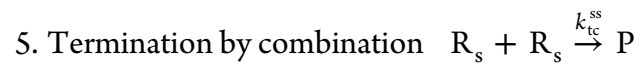

$$
\begin{aligned}
& \mathrm{R}_{\mathrm{t}}+\mathrm{R}_{\mathrm{t}} \stackrel{k_{\mathrm{tc}}^{\mathrm{tt}}}{\rightarrow} \mathrm{P} \\
& \mathrm{R}_{\mathrm{s}}+\mathrm{R}_{\mathrm{t}} \stackrel{k_{\mathrm{st}}^{\mathrm{st}}}{\rightarrow} \mathrm{P}
\end{aligned}
$$

where I represents the initiator species (in this case, KPS), $\mathrm{R}_{\mathrm{s}}=$ $\sum_{n=1}^{\infty} \mathrm{R}_{\mathrm{s}, n}$ is a pseudoradical that represents all radical species of type $\mathrm{s}$ (secondary radicals) independent of their chain length (as usual assumed in the frame of the so-called "terminal kinetic model", TMK), $\mathrm{R}_{\mathrm{t}}=\sum_{n=1}^{\infty} \mathrm{R}_{\mathrm{t}, n}$ is a pseudoradical that represents all radical species of type $t$ (tertiary radicals) independent of their chain length, $\mathrm{M}$ is the monomer (in this case, $\mathrm{BA}$ ), and $\mathrm{P}$ represents the dead polymer chain (neither branching nor molecular weight distribution analysis haas been considered according to the TMK theory). For the sake of simplicity, it is possible to consider all reaction rates corresponding to the above reactions independent by the phase (aqueous or polymer) where they occur. According to such a hypothesis, reaction rates can be expressed as follows:

$$
\begin{aligned}
& \text { 1. Initiation } \quad r_{i}=f_{w} k_{i}\left[\mathrm{I}_{2}\right] \\
& \begin{array}{l}
\text { 2. Propagation } \quad r_{\mathrm{p}}^{\mathrm{s}}=k_{\mathrm{p}}^{\mathrm{s}}[\mathrm{M}]\left[\mathrm{R}_{\mathrm{s}}\right] \\
\text { 3. Backbiting } \quad r_{\mathrm{bb}}=k_{\mathrm{bb}}\left[\mathrm{R}_{\mathrm{s}}\right] \\
\text { 4. Propagation from tertiary radicals } \quad r_{\mathrm{p}}^{\mathrm{t}}=k_{\mathrm{p}}^{\mathrm{t}}[\mathrm{M}]\left[\mathrm{R}_{\mathrm{t}}\right] \\
\text { 5. Termination by combination } \quad r_{\mathrm{tc}}^{\mathrm{ss}}=k_{\mathrm{tc}}^{\mathrm{ss}}\left[\mathrm{R}_{\mathrm{s}}\right]^{2} \\
r_{\mathrm{tc}}^{\mathrm{tt}}=k_{\mathrm{tc}}^{\mathrm{tt}}\left[\mathrm{R}_{\mathrm{t}}\right]^{2} \\
r_{\mathrm{tc}}^{\mathrm{st}}=k_{\mathrm{tc}}^{\mathrm{st}}\left[\mathrm{R}_{\mathrm{s}}\right]\left[\mathrm{R}_{\mathrm{t}}\right]
\end{array}
\end{aligned}
$$

The reactive steps (dosing and curing) can be modeled through the following system of differential-algebraic equations (DAEs; see the Nomenclature section for the meaning of the different symbols): dosing policy (first equation), isothermal temperature proportionalintegral-derivative control loop (second equation), energy balances on both the jacket (third equation) and reactor (fourth equation), global material balance (fifth equation), mixing rule (sixth equation), polymer particle concentration (seventh equation), radius evolution (eighth equation), micelle conversion (ninth equation), and all component [initiator (10th equation), radicals (11th through 14th 
equations), and monomer (15th equation)] material balances (for each required phase, aqueous and polymeric).

In the time range $0 \leq \vartheta<1$ :

$$
\begin{aligned}
& \frac{\mathrm{d} v_{\mathrm{dos}}}{\mathrm{d} \vartheta}=1 \\
& \frac{\mathrm{d} \tau_{\text {cool,in }}}{\mathrm{d} \vartheta}=-K_{\mathrm{pT}}\left[\frac{\mathrm{d} \tau}{\mathrm{d} \vartheta}-\frac{t_{\mathrm{dos}}}{K_{\mathrm{iT}}}\left(\tau_{\mathrm{set}}-\tau\right)+\frac{K_{\mathrm{dT}}}{t_{\mathrm{dos}}} \frac{\mathrm{d}^{2} \tau}{\mathrm{d} \vartheta^{2}}\right] \\
& \frac{\mathrm{d} \tau_{\text {cool }}}{\mathrm{d} \vartheta}=\theta_{\text {cool }}\left(\tau_{\text {cool,in }}-\tau_{\text {cool }}\right)+\operatorname{NTU} v\left(\tau-\tau_{\text {cool }}\right) \\
& \rho v \frac{\mathrm{d} \tau}{\mathrm{d} \vartheta}=\Delta \tau_{\mathrm{ad}} \frac{\mathrm{d} \zeta_{\mathrm{M}}}{\mathrm{d} \vartheta}+\frac{\mathrm{d} v_{\mathrm{dos}}}{\mathrm{d} \vartheta} \varepsilon R_{\mathrm{H}}\left(\tau_{\mathrm{dos}}-\tau\right) \\
& -S t \times v\left(\tau-\tau_{\text {cool }}\right)-S t_{\text {ext }}\left(\tau-\tau_{\text {ext }}\right) \\
& \frac{\mathrm{d} v}{\mathrm{~d} \vartheta}=\frac{\varepsilon}{\rho} \frac{\mathrm{d} v_{\mathrm{dos}}}{\mathrm{d} \vartheta}-\frac{v}{\rho} \frac{\mathrm{d} \rho}{\mathrm{d} \vartheta} \\
& \frac{\mathrm{d} \rho}{\mathrm{d} \vartheta}=\frac{\varepsilon \frac{\mathrm{d} v_{\mathrm{dos}}}{\mathrm{d} \vartheta}\left(1-\frac{\left(1-\alpha \zeta_{\mathrm{M}}\right)}{\rho_{\mathrm{dos}}}\right)+\alpha \frac{\varepsilon}{\rho_{\mathrm{dos}}} v_{\mathrm{dos}} \frac{\mathrm{d} \zeta_{\mathrm{M}}}{\mathrm{d} \vartheta}\left(1+\varepsilon v_{\mathrm{dos}}\right)}{\left(1+\frac{\varepsilon}{\rho_{\mathrm{dos}}} v_{\mathrm{dos}}\left(1-\alpha \zeta_{\mathrm{M}}\right)\right)^{2}} \\
& \frac{\mathrm{d} \eta}{\mathrm{d} \vartheta}=D a_{\text {nucl,mic }}^{\mathrm{s}} \zeta_{\mathrm{R}_{\mathrm{s}}}\left(1-\zeta_{\text {mic }}\right)+D a_{\text {nucl,mic }}^{\mathrm{t}} \zeta_{\mathrm{R}_{\mathrm{t}}}\left(1-\zeta_{\text {mic }}\right) \\
& +D a_{\text {nucl,omo,bis }}^{\mathrm{s}} \kappa_{\mathrm{p}}^{\mathrm{s}} \zeta_{\mathrm{R}_{\mathrm{s}}}+D a_{\text {nucl,omo,bis }}^{\mathrm{t}} \kappa_{\mathrm{p}}^{\mathrm{t}} \zeta_{\mathrm{R}_{\mathrm{t}}} \\
& -D a_{\text {coal }} \eta^{2} \sqrt{1-\zeta_{\mathrm{I}}} \\
& \frac{\mathrm{d} \delta}{\mathrm{d} \vartheta}=C_{\delta, \mathrm{s}} \kappa_{\mathrm{p}}^{\mathrm{s}} n_{\mathrm{s}} \delta^{-2}+C_{\delta, \mathrm{t}} \kappa_{\mathrm{p}}^{\mathrm{t}} n_{\mathrm{t}} \delta^{-2} \\
& \zeta_{\text {mic }}=\delta \eta \\
& \frac{\mathrm{d} \zeta_{\mathrm{I}}}{\mathrm{d} \vartheta}=D a_{i} \kappa_{i}\left(1-\zeta_{\mathrm{I}}\right) \\
& \frac{\mathrm{d} \zeta_{\mathrm{R}_{s} \mathrm{w}}}{\mathrm{d} \vartheta}=2 D a_{i} \kappa_{i}\left(1-\zeta_{\mathrm{I}}\right)+D a_{\mathrm{p}, \mathrm{w}}^{\mathrm{t}} \kappa_{\mathrm{p}}^{\mathrm{t}} \zeta_{\mathrm{R}_{\mathrm{t}}}-D a_{\mathrm{bb}, \mathrm{w}} \kappa_{\mathrm{bb}} \zeta_{\mathrm{R}_{\mathrm{s}}} \\
& -2 D a_{\mathrm{tc}, \mathrm{w}}^{\mathrm{ss}} \kappa_{\mathrm{tc}}^{\mathrm{ss}} \zeta_{\mathrm{R}_{\mathrm{s}}}{ }^{2}-D a_{\mathrm{tc}, \mathrm{w}}^{\mathrm{st}} \kappa_{\mathrm{tc}}^{\mathrm{st}} \zeta_{\mathrm{R}_{\mathrm{s}}} \zeta_{\mathrm{R}_{\mathrm{t}}}-D a_{\mathrm{diff}, \mathrm{wp}}^{\mathrm{s}} \zeta_{\mathrm{R}_{\mathrm{s}}} \\
& \times \eta \delta-D a_{\text {nucl,mic }}^{\mathrm{s}} \zeta_{\mathrm{R}_{\mathrm{s}}}\left(1-\zeta_{\mathrm{mic}}\right)-D a_{\text {nucl,omo }}^{\mathrm{s}} \kappa_{\mathrm{p}}^{\mathrm{s}} \zeta_{\mathrm{R}_{\mathrm{s}}} \\
& +D a_{\text {diff,pw }}^{\mathrm{s}} n_{\mathrm{s}} \eta^{2} \delta \\
& \frac{\mathrm{d} \zeta_{\mathrm{R}_{\mathrm{t}}}}{\mathrm{d} \vartheta}=-D a_{\mathrm{p}, \mathrm{w}}^{\mathrm{t}} \kappa_{\mathrm{p}}^{\mathrm{t}} \zeta_{\mathrm{R}_{\mathrm{t}}}+D a_{\mathrm{bb}, \mathrm{w}} \kappa_{\mathrm{bb}} \zeta_{\mathrm{R}_{\mathrm{s}}}-2 D a_{\mathrm{tc}, \mathrm{w}}^{\mathrm{tt}} \kappa_{\mathrm{tc}}^{\mathrm{tt}} \zeta_{\mathrm{R}_{\mathrm{t}}}{ }^{2} \\
& -D a_{\mathrm{tc}, \mathrm{w}}^{\mathrm{st}} \kappa_{\mathrm{tc}}^{\mathrm{st}} \zeta_{\mathrm{R}_{\mathrm{s}}} \zeta_{\mathrm{R}_{\mathrm{t}}}-D a_{\mathrm{diff,wp}}^{\mathrm{t}} \zeta_{\mathrm{R}_{\mathrm{t}}} \eta \delta-D a_{\mathrm{nucl,mic}}^{\mathrm{t}} \\
& \times \zeta_{\mathrm{R}_{\mathrm{t}}}\left(1-\zeta_{\text {mic }}\right)-D a_{\text {nucl,omo }}^{\mathrm{t}} \kappa_{\mathrm{p}}^{\mathrm{t}} \zeta_{\mathrm{R}_{\mathrm{t}}}+D a_{\text {diff,pw }}^{\mathrm{t}} n_{\mathrm{t}} \eta^{2} \delta \\
& \frac{\mathrm{d} n_{\mathrm{s}}}{\mathrm{d} \vartheta}=D a_{\mathrm{p}, \mathrm{p}}^{\mathrm{t}} \kappa_{\mathrm{p}}^{\mathrm{t}} n_{\mathrm{t}}-D a_{\mathrm{tc}, \mathrm{p}}^{\mathrm{ss}} \kappa_{\mathrm{tc}}^{\mathrm{ss}} \frac{n_{\mathrm{s}}\left(n_{\mathrm{s}}-1\right)}{\delta^{3}}-D a_{\mathrm{tc}, \mathrm{p}}^{\mathrm{st}} \kappa_{\mathrm{tc}}^{\mathrm{st}} \frac{n_{\mathrm{s}} n_{\mathrm{t}}}{\delta^{3}} \\
& -D a_{\mathrm{bb}, \mathrm{p}} \kappa_{\mathrm{bb}} n_{\mathrm{s}}+C_{\mathrm{diff,wp}}^{\mathrm{s}} \zeta_{\mathrm{s}} \delta-C_{\mathrm{diff}, \mathrm{pw}}^{\mathrm{s}} \eta n_{\mathrm{s}} \delta \\
& \frac{\mathrm{d} n_{\mathrm{t}}}{\mathrm{d} \vartheta}=-D a_{\mathrm{p}, \mathrm{p}}^{\mathrm{t}} \kappa_{\mathrm{p}}^{\mathrm{t}} n_{\mathrm{t}}-D a_{\mathrm{tc}, \mathrm{p}}^{\mathrm{tt}} \kappa_{\mathrm{tc}}^{\mathrm{tt}} \frac{n_{\mathrm{t}}\left(n_{\mathrm{t}}-1\right)}{\delta^{3}}-D a_{\mathrm{tc}, \mathrm{p}}^{\mathrm{st}} \kappa_{\mathrm{tc}}^{\mathrm{st}} \frac{n_{\mathrm{s}} n_{\mathrm{t}}}{\delta^{3}} \\
& +D a_{\mathrm{bb}, \mathrm{p}} \kappa_{\mathrm{bb}} n_{\mathrm{s}}+C_{\mathrm{diff,xp}}{ }^{t} \zeta_{\mathrm{R}_{\mathrm{t}}} \delta-C_{\mathrm{diff,wp}}^{\mathrm{t}} \eta n_{\mathrm{t}} \delta \\
& \frac{\mathrm{d} \zeta_{\mathrm{M}}}{\mathrm{d} \vartheta}=D a_{\mathrm{pM}}^{\mathrm{s}} \kappa_{\mathrm{p}}^{\mathrm{s}}\left[[\mathrm{I}]_{0} \zeta_{\mathrm{R}_{\mathrm{s}}}+\frac{\left[N_{\mathrm{mic}}\right]_{\mathrm{w}, 0}}{N_{\mathrm{A}}} n_{\mathrm{s}} \eta\right]\left[\frac{\left(v_{\mathrm{dos}}-\zeta_{\mathrm{M}}\right)}{v}\right] \\
& +D a_{\mathrm{pM}}^{\mathrm{t}} \kappa_{\mathrm{p}}^{\mathrm{t}}\left[[\mathrm{I}]_{0} \zeta_{\mathrm{R}_{\mathrm{t}}}+\frac{\left[N_{\mathrm{mic}}\right]_{\mathrm{w}, 0}}{N_{\mathrm{A}}} n_{\mathrm{t}} \eta\right]\left[\frac{\left(v_{\mathrm{dos}}-\zeta_{\mathrm{M}}\right)}{v}\right]
\end{aligned}
$$

This DAE system has to be solved together with the following initial conditions for $\vartheta=0$ :

$$
\begin{gathered}
v_{\text {dos }}=0, \quad \tau_{\text {cool, in }}=\tau_{\text {cool, }, \text { in }, 0}, \tau_{\text {cool }}=\tau_{\text {cool }, 0}, \tau=\tau_{0}, \quad v=1, \\
\rho=1, \quad \eta=0, \delta=1, \quad \zeta_{\mathrm{I}}=0, \quad \zeta_{\mathrm{R}_{\mathrm{s}}}=0, \quad \zeta_{\mathrm{R}_{\mathrm{t}}}=0, \\
n_{\mathrm{s}}=0, \quad n_{\mathrm{t}}=0, \quad \zeta_{\mathrm{M}}=0
\end{gathered}
$$

Some of the equations above change for $\vartheta \geq 1$ as follows:

$$
\begin{aligned}
& \frac{\mathrm{d} v_{\mathrm{dos}}}{\mathrm{d} \vartheta}=0 \\
& \frac{\mathrm{d} v}{\mathrm{~d} \vartheta}=-\frac{v}{\rho} \frac{\mathrm{d} \rho}{\mathrm{d} \vartheta} \\
& \frac{\mathrm{d} \rho}{\mathrm{d} \vartheta}=\frac{\alpha \frac{(1+\varepsilon) \varepsilon}{\rho_{\text {dos }}} \frac{\mathrm{d} \zeta_{\mathrm{M}}}{\mathrm{d} \vartheta}}{\left(1+\frac{\varepsilon}{\rho_{\mathrm{dos}}}\left(1-\alpha \zeta_{\mathrm{M}}\right)\right)^{2}} \\
& \rho v \frac{\mathrm{d} \tau}{\mathrm{d} \vartheta}=\Delta \tau_{\mathrm{ad}} \frac{\mathrm{d} \zeta_{\mathrm{M}}}{\mathrm{d} \vartheta}-S t \times v\left(\tau-\tau_{\text {cool }}\right)-S t_{\text {ext }}\left(\tau-\tau_{\text {ext }}\right)
\end{aligned}
$$

Note that radical diffusion (inside and outside the micelle/ polymer particles) and homogeneous (in water) and micelle nucleation with polymer particle coagulation phenomena have also been considered. ${ }^{32}$ Moreover, in the energy balance equation, the following heat contributions have been considered: heat accumulation (left-hand side) responsible for the temperature increase during the process, heat evolution (first term on the right-hand side) accounting for the heat developed by all exothermic reactions (in this case, only the propagation reaction), heat removal due to the dosing stream action (second term on the right-hand side, which disappears for times larger than the dosing one), heat removal due to the cooling jacket action (third term on the right-hand side), and heat removal due to both ambient dispersions and evaporation losses (fourth term on the right-hand side).

\section{AUTHOR INFORMATION}

\section{Corresponding Author}

*Fax: +39 0223993180. E-mail: renato.rota@polimi.it.

\section{Notes}

The authors declare no competing financial interest.

\section{ACKNOWLEDGMENTS}

The authors express their gratitude to Prof. G. Storti for his precious suggestions about emulsion polymerization theory and L. Sacchetti, U. Vismara, C. Pasturenzi, L. Gigante, and M. Dellavedova for part of the laboratory experimentations.

\section{NOMENCLATURE}

A preexponential factor $\left[\mathrm{s}^{-1}\right.$ or $\left.\mathrm{m}^{3} \cdot \mathrm{s} / \mathrm{kmol}\right]$ or area $\left[\mathrm{m}^{2}\right]$

$C_{\text {diff,pw }} \quad k_{\text {diff,wp }, 0} \times 4 \pi r_{\text {mic }}^{2} N_{\mathrm{A}}[\mathrm{I}]_{0} t_{\text {dos }}$, global constant for radical diffusion from polymer particles to water

$C_{\text {diff,wp }} \quad k_{\text {diff,wp }, 0} \times 4 \pi r_{\text {mic }}^{2} N_{\mathrm{A}}[\mathrm{mic}]_{0} t_{\text {dos }}$, global constant for radical diffusion from water to polymer particles

$C_{\delta} \quad k_{\mathrm{p}, \mathrm{rif}} t_{\mathrm{dos}}\left[\varepsilon_{\mathrm{mp}} /\left(1-\varepsilon_{\mathrm{mp}}\right)\right]\left(\rho_{\mathrm{M}} / \rho_{\mathrm{P}}\right)\left(1 / N_{\mathrm{A}}\right)\left(1 / 4 \pi v_{\text {mic }}\right)$, volume increase constant for a polymer particle specific heat capacity $[\mathrm{J} /(\mathrm{kg} \cdot \mathrm{K})]$ diffusion coefficient $\left[\mathrm{m}^{2} / \mathrm{s}\right]$ 


\begin{tabular}{|c|c|}
\hline$D a_{\mathrm{bb}}$ & $\begin{array}{l}k_{\text {bb,rif }} t_{\text {dos }} \text { Damköhler number for the backbiting } \\
\text { reaction }\end{array}$ \\
\hline$D a_{\text {coal }}$ & $\begin{array}{l}k_{\text {coal }}\left([\mathrm{I}]_{0} V_{0} N_{\mathrm{A}}\right)^{1 / 2}[\mathrm{mic}]_{0} V_{0} t_{\text {dos }} \text {, Damköhler number } \\
\text { for coalescence of the polymer particles }\end{array}$ \\
\hline$D a_{\text {diff,pw }}$ & $\begin{array}{l}k_{\text {diff,pw }} \cdot[\mathrm{mic}]_{0}^{2} \times 4 \pi r_{\text {mic }}^{2} t_{\text {dos }} /[\mathrm{I}]_{0} N_{\mathrm{A}} \text {, Damköhler } \\
\text { number for radical diffusion from polymer particles } \\
\text { to water }\end{array}$ \\
\hline$D a_{\text {diff,wp }}$ & $\begin{array}{l}k_{\text {diff,wp }} \times 4 \pi r_{\text {mic }}^{2}[\mathrm{mic}]_{0} t_{\text {dos }} \text {, Damköhler number for } \\
\text { radical diffusion from water to polymer particles }\end{array}$ \\
\hline$D a_{i}$ & $\begin{array}{l}f_{\mathrm{w}} k_{\mathrm{i}, \mathrm{rit}} t_{\mathrm{dos}} \text {, Damköhler number for the initiation } \\
\text { reaction (in water) }\end{array}$ \\
\hline$D a_{\text {nucl,mic }}$ & $\begin{array}{l}4 \pi D_{\text {diff,wp }} r_{\text {mic }} f_{\text {nucl,mic }}[\mathrm{mic}]_{0} t_{\text {dos }} \text {, Damköhler number } \\
\text { for micellar nucleation }\end{array}$ \\
\hline$D a_{\text {nucl,omo }}$ & $\begin{array}{l}k_{\text {nucl,omo }} k_{\mathrm{p}, \text { rif }}[\mathrm{M}]_{\mathrm{w}, \text { sat }} t_{\mathrm{dos}} \text {, Damköhler number for } \\
\text { homogeneous nucleation }\end{array}$ \\
\hline$D a_{\text {nucl,omo,bis }}$ & $\begin{array}{l}k_{\text {nucl,omo }} k_{\mathrm{p}, \text { rif }}[\mathrm{M}]_{\mathrm{w}, \text { sat }}\left([\mathrm{I}]_{0} N_{\mathrm{A}} /[\mathrm{mic}]_{0}\right) t_{\mathrm{dos}} \text {, Damköhler } \\
\text { number for homogeneous nucleation (variation) }\end{array}$ \\
\hline$D a_{\mathrm{pM}}$ & $\begin{array}{l}k_{\text {p,rif }} t_{\text {dos }} \text {, Damköhler number for the global prop- } \\
\text { agation reaction }\end{array}$ \\
\hline$D a_{\mathrm{p}, \mathrm{p}}$ & $\begin{array}{l}k_{\mathrm{p}, \text { rif }}[\mathrm{M}]_{\mathrm{p} \text {,sat }} t_{\mathrm{dos}} \text {, Damköhler number for the prop- } \\
\text { agation reaction in the polymeric phase }\end{array}$ \\
\hline$D a_{\mathrm{p}, \mathrm{w}}$ & $\begin{array}{l}k_{\mathrm{p}, \text { rif }}[\mathrm{M}]_{\mathrm{w}, \mathrm{sat}} t_{\mathrm{dos}} \text {, Damköhler number for the prop- } \\
\text { agation reaction in the aqueous phase }\end{array}$ \\
\hline$D a_{\mathrm{tc}, \mathrm{p}}$ & $\begin{array}{l}\left(k_{\mathrm{ic}, \text { rif }} / v_{\text {mic }} N_{\mathrm{A}}\right) t_{\mathrm{dos}} \text {, Damköhler number for the } \\
\text { termination reaction in the polymer phase }\end{array}$ \\
\hline$D a_{\mathrm{tc}, \mathrm{w}}$ & $\begin{array}{l}k_{\mathrm{tc}, \mathrm{rif}}[\mathrm{I}]_{0} t_{\mathrm{dos}}, \text { Damköhler number for the termination } \\
\text { reaction in the aqueous phase }\end{array}$ \\
\hline$E_{\text {att }}$ & activation energy $[\mathrm{kJ} / \mathrm{kmol}]$ \\
\hline & micellar nucleation efficiency \\
\hline & $\begin{array}{l}\text { initiator thermal decomposition efficiency (in } \\
\text { water) }\end{array}$ \\
\hline$\Delta \tilde{H}_{\mathrm{rxn}}$ & action enthalpy $[\mathrm{J} / \mathrm{kmol}]$ \\
\hline$K_{\mathrm{dT}}$ & derivative time $[\mathrm{s}]$ \\
\hline$K_{\mathrm{iT}}$ & 60 , reset time $[\mathrm{s}]$ \\
\hline$K_{\mathrm{pT}}$ & 6 , proportional gain \\
\hline$k^{\mathrm{Pt}}$ & $\begin{array}{l}A \exp \left(-E_{\text {att }} / R T\right) \text {, kinetic constant }\left[\mathrm{s}^{-1} \text { or } \mathrm{m}^{3} \cdot \mathrm{s} /\right. \\
\mathrm{kmol}]\end{array}$ \\
\hline$k_{\text {coal }}$ & kinetic constant for polymer particle coalescence \\
\hline$k_{\text {diff }}$ & c constant for ra \\
\hline$k_{\text {nucl,omo }}$ & ant for homogeneous nuclea \\
\hline I & ecies \\
\hline$m$ & acting mass $[\mathrm{kg}]$ \\
\hline M & ner species \\
\hline MAT & Im allowable temperature $\left[{ }^{\circ} \mathrm{C}\right.$ or $\left.\mathrm{K}\right]$ \\
\hline MW & ular weight $[\mathrm{kg} / \mathrm{kr}$ \\
\hline$n$ & $\begin{array}{l}\text { In index, number of monomer units in a radical } \\
\text { ain, number of moles }[\mathrm{kmol}] \text {, or number of } \\
\text { eecies units }\end{array}$ \\
\hline$N_{\mathrm{A}}$ & $6.022 \times 10^{26}$, Avogadro's number $\left[\mathrm{kmol}^{-1}\right]$ \\
\hline $\begin{array}{l}\text { NTU } \\
\text { P }\end{array}$ & $\begin{array}{l}\left.\mathrm{UA}_{0} t_{\text {doo }} / \hat{p}_{\text {cool }} \hat{c}_{\text {p,cool }} V_{\text {cool }}\right) \text {, number of transfer units } \\
\text { dead polymer chain }\end{array}$ \\
\hline $\mathrm{R}$ & $\begin{array}{l}\text { gas constant }=8314[\mathrm{~J} /(\mathrm{kmol} \cdot \mathrm{K})] \text { or generic } \\
\text { pseudoradical species }\end{array}$ \\
\hline$R_{\mathrm{H}}$ & $\hat{c}_{\mathrm{p}, \mathrm{dos}} / \hat{c}_{\mathrm{p}, \text { mix }}$ heat capacity ratio \\
\hline RW & unaway operating conditions \\
\hline$r$ & particle radius $[\mathrm{m}]$ \\
\hline STV & tarving conditions \\
\hline St & $\mathrm{UA}_{0} t_{\mathrm{dos}} / \hat{p}_{0} \hat{c}_{\mathrm{p}, \text { mix }} V_{0}$ or Stanton number \\
\hline$S t_{\text {ext }}$ & $\begin{array}{l}\mathrm{UA}_{\text {ext }} t_{\text {dos }} / \hat{p}_{0} \hat{c}_{\mathrm{p} \text {,mix }} V_{0} \text { or Stanton number referred to } \\
\text { ambient dispersion and evaporation losses }\end{array}$ \\
\hline & \\
\hline$T$ & $\lceil V\rceil$ \\
\hline$U$ & rerall heat-transfer coefficient $\left[\mathrm{W} /\left(\mathrm{m}^{2} \cdot \mathrm{K}\right)\right]$ \\
\hline
\end{tabular}

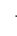

$V \quad$ volume $\left[\mathrm{m}^{3}\right]$

$\dot{V} \quad$ volumetric flow rate $\left[\mathrm{m}^{3} / \mathrm{s}\right]$

$v \quad V / V_{0}$, dimensionless reactor volume

$v_{\text {dos }} \quad V_{\text {dos }} / V_{\text {TOT,dos }}$, dimensionless dosing volume

\section{Subscripts and Superscripts}

att activation energy

ad adiabatic

cool coolant or external jacket

dos dosing stream or dosing time

ext external heat losses

in inlet stream

i initiation reaction

$j \quad$ index of the dosing times

max maximum value of a quantity or at the maximum value of a quantity

min minimum value of a quantity or at the minimum value of a quantity

mic micelles

mix reaction mixture

$\mathrm{p} \quad$ propagation reaction or polymer particles

QFS “quick onset, fair conversion, and smooth temperature profile"

rif reference conditions

$S$, s radical species of type $s$

sat saturation value

set desired set point

$T, t$ radical species of type $t$

TOT total amount

w continuous phase (water)

0 start of the dosing period

\section{Greek Symbols}

$\alpha \quad 1-\hat{p}_{\mathrm{M}} / \hat{p}_{\mathrm{P}}$, volume contraction when monomer is converted in a dead chain

$\left.\Delta \tau_{\text {ad }}-\Delta \tilde{H}_{\text {rxn }}[\mathrm{M}]_{\text {dos }}\right) / \hat{p}_{0} \hat{c}_{\text {p,mix }} T_{\text {rif, }}$ dimensionless adiabatic temperature rise

$\delta \quad r / r_{\text {mic }}$ dimensionless polymer particles radius

$\varepsilon_{\mathrm{mp}} \quad[\mathrm{M}]_{\mathrm{p}, \mathrm{sat}} \mathrm{MW}_{\mathrm{M}} / \hat{p}_{\mathrm{M}}$, ratio between the monomer volume and polymer particle volume when the monomeric phase still exists

$\gamma \quad E_{\text {att }} / R T_{\text {rif }}$, dimensionless activation energy

$\varepsilon \quad m_{\mathrm{TOT}, \mathrm{dos}} / m_{0}$, relative mass increase at the end of the semibatch period

$\zeta$ dimensionless concentration or conversion of a generic species

$\eta \quad[\mathrm{P}]_{\mathrm{w}} /[\mathrm{mic}]_{0}$, dimensionless polymer particle concentration (in water)

$\kappa \quad \exp [\gamma(1-1 / \tau)]$, dimensionless kinetic constant

$\rho \quad \hat{p} / \hat{p}_{0}$, dimensionless reaction mixture density

$\hat{p} \quad$ reaction mixture density $\left[\mathrm{kg} / \mathrm{m}^{3}\right]$

$\theta \quad \dot{V}_{\text {cool }} t_{\text {dos }} / V_{\text {cool, }}$ dimensionless coolant contact frequency into the jacket

$\vartheta \quad t / t_{\text {dos }}$, dimensionless time

$\tau \quad T / T_{\text {rif }}$ dimensionless temperature

$\Psi \quad T / T_{0}$, dimensionless temperature with respect to the initial reactor temperature

\section{REFERENCES}

(1) Hugo, P.; Steinbach, J. A comparison of the limits of safe operation of a SBR and a CSTR. Chem. Eng. Sci. 1986, 41, 1081.

(2) Steensma, M.; Westerterp, K. R. Thermally safe operation of a semibatch reactor for liquid-liquid reactions. Slow reactions. Ind. Eng. Chem. Res. 1990, 29, 1259. 
(3) Alós, M. A.; Nomen, R.; Sempere, J.; Strozzi, F.; Zaldívar, J. M. Generalized criteria for boundary safe conditions in semi-batch processes: simulated analysis and experimental results. Chem. Eng. Prog. 1998, 37, 405.

(4) Varma, A.; Morbidelli, M.; Wu, H. Parametric Sensitivity in Chemical Systems; Cambridge University Press: Cambridge, U.K., 1999.

(5) Strozzi, F.; Zaldívar, J. M.; Kronberg, A. E.; Westerterp, K. R. Online runaway detection in batch reactors using chaos theory techniques. AIChE J. 1999, 45, 2429.

(6) Zaldívar, J. M.; Cano, J.; Alós, M. A.; Sempere, J.; Nomen, R.; Lister, D.; Maschio, G.; Obertopp, T.; Gilles, E. D.; Bosch, J.; Strozzi, F. A general criterion to define runaway limits in chemical reactors. J. Loss Prev. Process Ind. 2003, 16, 187.

(7) Bosch, J.; Strozzi, F.; Lister, D. G.; Maschio, G.; Zaldívar, J. M. Sensitivity Analysis in Polymerization Reactions Using the Divergence Criterion. Process Saf. Environ. Prot. 2004, 81, 18.

(8) Casson, V.; Lister, D. G.; Milazzo, M. F.; Maschio, G. Comparison of criteria for prediction of runaway reactions in the sulphuric acid catalyzed esterification of acetic anhydride and methanol. J. Loss Prev. Process Ind. 2012, 25, 209.

(9) Bosch, J.; Strozzi, F.; Zbilut, J. P.; Zaldivar, J. M. On-line runaway detection in isoperibolic batch and semibatch reactors using the divergence criterion. Comput. Chem. Eng. 2004, 28, 527.

(10) Westerterp, K. R.; Molga, E. J. No more runaways in fine chemical reactors. Ind. Eng. Chem. Res. 2004, 43, 4585.

(11) Westerterp, K. R.; Molga, E. J. Safety and runaway prevention in batch and semibatch reactors-A review. Chem. Eng. Res. Des. 2006, 84, 543.

(12) Copelli, S.; Derudi, M.; Rota, R. Topological criteria to safely optimize hazardous chemical processes involving consecutive reactions. Ind. Eng. Chem. Res. 2010, 49, 4583.

(13) Copelli, S.; Derudi, M.; Rota, R. Topological criterion to safely optimize hazardous chemical processes involving arbitrary kinetic schemes. Ind. Eng. Chem. Res. 2011, 50, 1588.

(14) Nolan, P. F.; Barton, J. A. Some lessons from thermal-runaway incidents. J. Hazard. Mater. 1987, 14, 233.

(15) Brandrup, J.; Immergut, E. H.; Grulke, E. A.; Abe, A.; Bloch, D. R. Polymer Handbook, 4th ed.; John Wiley \& Sons: Hoboken, NJ, 1999.

(16) Trommsdorff, E.; Köhle, H.; Lagally, P. Zur polymerisation des methacrylsäuremethylesters. Makromol. Chem. 1948, 1, 169.

(17) Alger, M. Polymer Science Dictionary; Elsevier Applied Science: New York, 1989.

(18) Maestri, F.; Rota, R. Temperature diagrams for preventing decomposition or side reactions in liquid-liquid semibatch reactors. Chem. Eng. Sci. 2006, 61, 3068.

(19) Chern, C. S. Emulsion polymerization mechanisms and kinetics. Prog. Polym. Sci. 2006, 31, 443.

(20) Erbil, Y. H. Vinyl acetate emulsion polymerization and copolymerization with acrylic monomers; CLC Press LLC: Boca Raton, FL, 2000.

(21) Steensma, M.; Westerterp, K. R. Thermally safe operation of a cooled semi-batch reactor. Slow liquid-liquid reactions. Chem. Eng. Sci. 1988, 43, 2125.

(22) Maestri, F.; Rota, R. Thermally safe operation of liquid-liquid semibatch reactors. Part I: Single kinetically controlled reactions with arbitrary reaction order. Chem. Eng. Sci. 2005, 60, 3309.

(23) Maestri, F.; Rota, R. Thermally safe operation of liquid-liquid semibatch reactors. Part II: Single diffusion controlled reactions with arbitrary reaction order. Chem. Eng. Sci. 2005, 60, 5590.

(24) Maestri, F.; Copelli, S.; Rota, R.; Gigante, L.; Lunghi, A.; Cardillo, P. Simple procedure for optimally scaling-up fine chemical processes. I. Practical tools. Ind. Eng. Chem. Res. 2009, 48, 1307.

(25) Copelli, S.; Derudi, M.; Lunghi, A.; Pasturenzi, C.; Rota, R. Experimental Design of Topological Curves to Safely Optimize Highly Exothermic Complex Reacting Systems. Ind. Eng. Chem. Res. 2011, 50, 9910.

(26) Copelli, S.; Derudi, M.; Rota, R.; Torretta, V.; Pasturenzi, C.; Lunghi, A. Safe optimization of 2-octanol oxidation and vinyl acetate emulsion polymerization. Chem. Eng. Trans. 2012, 26, 21.
(27) Copelli, S.; Derudi, M.; Sempere, J.; Serra, E.; Lunghi, A.; Pasturenzi, C.; Rota, R. Emulsion polymerization of vinyl acetate: safe optimization of a hazardous complex process. J. Hazard. Mater. 2011, $192,8$.

(28) Gonzáles, I.; Leiza, J. R.; Asua, M. Exploring the limits of branching and gel content in the emulsion polymerization of n-BA. Macromolecules 2006, 39, 5015.

(29) Asua, J. M.; Beuermann, S.; Buback, M.; Castignolles, P.; Charleux, B.; Gilbert, R. G.; Hutchinson, R. A.; Leiza, J. R.; Nikitin, A. N.; Vairon, J. P.; van Herk, A. M. Critically evaluated rate coefficients for free-radical polymerizations-Propagation rate coefficient for butyl acrylate. Macromol. Chem. Phys. 2004, 205, 2151.

(30) Nikitin, A. N.; Hutchinson, R. A.; Buback, M.; Hesse, P. Determination of intramolecular chain transfer and midchain radical propagation rate coefficients for butyl acrylate by pulsed laser polymerization. Macromolecules 2007, 40, 8631.

(31) Beuermann, S.; Buback, M. Rate coefficients of free-radical polymerization deduced from pulsed laser experiments. Prog. Polym. Sci. 2002, 27, 191

(32) Sayer, C.; Palma, M.; Giudici, R. Modeling continuous vinyl acetate emulsion polymerization reactions in a pulsed laser sieve plate column. Ind. Eng. Chem. Res. 2002, 41, 1733. 